\section{Barrett's Esophagus in the Esophageal Remnant: A Critical Long-Term Complication of Subtotal Esophagectomy}

We read with interest the article by da Rocha et al. ${ }^{1}$ The authors are to be congratulated for their outstanding report. A 10-year follow-up on 101 post-esophagectomy and gastric interposition patients, for a benign condition, is an impressive contribution to the field of esophageal reconstruction. As emphasized by the authors, gastric interposition creates an in vivo human model of pathologic esophageal reflux with the known long-term potential complications. Of interest are those five patients who developed three squamous cell carcinomas and two adenocarcinomas in their esophageal remnant. The cascade from metaplasia to dysplasia and neoplasia is discussed.

We came to the same conclusions following our literature review and our recent evaluation of the esophageal mucosa pathology in 84 post-esophagectomy patients with a gastric interposition. ${ }^{2,3}$ Our results suggest that the prevalence of columnar metaplasia in the esophageal remnant increases over time with either a reconstruction in the chest or in the neck. Mucosal damage is evident in $28 \%$ of patients in less than 12 months, increases to $49 \%$ between 1 and 3 years, and is observed in $76 \%$ of the regularly assessed cohort beyond 3 years. The appearance of specialized intestinal metaplasia follows the same trend, being seen in $13 \%$ of patients during the first year, in $34 \%$ of them between 1 and 3 years, and in $40 \%$ of them three or more years after the anastomosis. We agree with the use of a cervical anastomosis for reconstruction in patients with a benign condition. In our hands a left cervical anastomosis favors less reflux symptoms, less visualized damage, and delays the development of mucosal damage over time. ${ }^{3}$

A number of questions come to mind after reading da Rocha's report. First, what interpretation do the authors give to the appearance of the three squamous cell carcinoma in their patients? Did chronic inflammation cause the same dysplastic changes in the squamous epithelium? In those patients with a columnar metaplasia on follow-up, was progression observed from metaplasia to dysplasia and finally neoplasia, specifically in those two patients who progressed to adenocarcinoma formation? With the actual evidence of mucosal damage from reflux disease and the appearance of malignant transformation in $10 \%$ of patients with intestinal metaplasia, is there any role for medical prevention of these changes with either proton pump inhibitor (PPI) or anti-H2 medication? Beside the thinner gastric tube proposed by the authors, are operations directed to the suppression of reflux events after gastric interposition considered by the authors?

Da Rocha highlights the imperfection of the solution that we offer so often and so easily to patients undergoing esophagectomy. Gastric interposition remains far from ideal as an esophageal substitute. Reflux esophagitis and new columnar lined metaplasia should be seen as a significant complication of esophagectomy with gastric interposition. At present, routine endoscopic surveillance remains the only available method to document mucosal damage and to rule out potential dysplastic changes in the columnar lined mucosa of the esophageal remnant.

Xavier Benoit D'Journo, MD, Pasquale Ferraro, MD, Jocelyne Martin, MD, and André Duranceau, MD

Division of Thoracic Surgery, Department of Surgery, Centre Hospitalier de l'Université de Montreal, Université de Montréal, Montreal, QC H2L 4M1, Canada

e-mail: andre.duranceau@umontreal.ca

Published Online: 29 January 2009

(C) Society of Surgical Oncology 2009

\section{REFERENCES}

1. da Rocha JR, Ribeiro U Jr, Sallum RA, Szachnowicz S, Cecconello I. Barrett's esophagus (BE) and carcinoma in the esophageal stump (ES) after esophagectomy with gastric pull-up in achalasia patients: a study based on 10 years follow-up. Ann Surg Oncol. 2008;15:2903-9.

2. D'Journo XB, Martin J, Ferraro P, Duranceau A. The esophageal remnant after gastric interposition. Dis Esophagus. 2008;21:37788.

3. D'Journo XB, Martin J, Rakovich G, Brigand C, Gaboury L, Ferraro P, et al. Mucosal damage in the esophageal remnant after esophagectomy and gastric transposition. Ann Surg. in press (electronic pre-print publication). 